\title{
Changes in water intake of adolescents between 1980 and 2000
}

\author{
Changes in water intake of Northumbrian adolescents 1980 to 2000 F. V. Zohouri, A. J. Rugg-Gunn, E. S. \\ Fletcher, A. F. Hackett, P. J. Moynihan, J. C. Mathers, and A. J. Adamson Br Dent J 2004; 196: 547-552
}

\section{Objectives}

To determine total water intake in young English adolescents; the relative importance of sources of water intake; and changes in water intake and sources of water between 1980 and 2000.

\section{Design}

A cross-sectional observational study of the diets of 11-12-yearold children attending 7 schools in south Northumberland, UK. The information obtained was compared with results from a similar survey carried out 20 years previously.

\section{Methods}

All children attending these schools were invited to participate. They completed a 3-day diet diary, with an interview on the fourth day, on two occasions during the school year. Standard UK food composition tables were used and water intake from various sources calculated. Anthropometric and social class information was obtained.

\section{Results}

Four hundred and twenty-four children completed all aspects of the study (64\% of those eligible). The mean total water intake was $1,130 \mathrm{~g} \mathrm{~d}^{-1}$, approximately the same as that recorded 20 years before. Water intake in relation to energy intake: water intake was $139 \mathrm{~g} \mathrm{MJ}^{-1}$ in boys and $143 \mathrm{~g} \mathrm{MJ}^{-1}$ in girls. Sixty-five per cent of water came from drinks and 35\% from foods; very similar to proportions 20 years before. The sources of water in drinks had changed considerably, with a marked increase in consumption of soft drinks (especially carbonated drinks) and a decrease in consumption of hot drinks and milk. There were a few differences between sexes but little difference between social groups.

\section{Conclusions}

Total water intake was similar to that recorded 20 years previously and lower than intakes reported in other countries. Changes in the sources of water meant that less water consumed was likely to come from the tap in the house and more from drinks made elsewhere, than 20 years previously. These changes have implications for estimating fluoride intake in fluoridated areas.

\section{IN BRIEF}

- Water is an important vehicle for fluoride and knowing the amount of fluoride ingested from fluoridated water is important for general and dental health.

- There is very little information on water intake in this country and world-wide. This study shows that water intake is less than commonly assumed. The present data show water intake to be similar to levels reported 20 years ago, but lower than some other countries.

- There has been a shift in the last 20 years to greater consumption of soft drinks and less consumption of milk and tea, in English adolescents.

\section{COMMENT}

Surprisingly, very few studies have been undertaken of the tota water intake of children and adolescents. Even major UK surveys of diet like the National Diet and Nutrition Surveys, whilst measuring the consumption of tap and bottled water have not included water contained within foods in their analysis.

Zohouri etal. not only measured total water intake but also very sensibly differentiated between consumer-added water and manufacturer-added water which could be derived from water supplies far distant from the locality in which the water was consumed; an important consideration in a fluoridated area. The latter appears to be an increasing source of total water intake. Importantly the study design also allowed comparisons to be made with a similar study undertaken 20 years previously, thereby enabling consumption trends to be determined.

This study found little difference between the total water intake of young adolescent children over a period of twenty years including the proportional intake of water from foods or drinks. However, significant differences were found between the sources of water. A large increase in the proportion of water consumed from soft drinks was found and conversely a significant decrease in the consumption of hot drinks and milk. This is important as tea is a source of natural fluoride and milk is an important nutritional food.

In a fluoridated area like Northumberland, the total consumption of water from public water supplies is an important determinant of the likely effectiveness of water fluoridation as a public health measure. Of major concern from this study is the finding that a potentially large reduction in mean fluoride intake had occurred over twenty years with daily levels of fluoride intake in 2000 lower than the optimal level.

The rise in the consumption of carbonated soft drinks coupled with a reduction in water intake either straight from the tap or in hot drinks and milk demonstrated by this study, should be of concern to all of us. Non-low calorie soft drinks are the main source of non-milk extrinsic (NME) sugars, and soft drinks as a whole make the largest contribution to the overall weight of acidic foods ingested. ${ }^{1}$

A. Jenner, Consultant in Dental Public Health, Office of the Chief Dental Officer, Department of Health, London

1. National Diet and Nutrition Survey - young people aged 4-18 years. London: The Stationery Office, 2000.

doi:10.1038/sj.bdj.4811240 